\title{
Evaluation of the volatile compound basil leaf (Ocimum basilicum) intervention on Spirulina platensis
}

\author{
${ }^{1}$ Yuliani, ${ }^{2, *}$ Agustini, T.W. and ${ }^{2}$ Dewi, E.N. \\ ${ }^{1}$ Department of Aquatic Resources, Faculty of Fisheries and Marine Sciences, Diponegoro University, \\ Semarang 50275 Indonesia \\ ${ }^{2}$ Department of Fisheries Technology, Faculty of Fisheries and Marine Science, Diponegoro University, \\ Semarang 50275, Indonesia
}

\section{Article history:}

Received: 9 February 2021

Received in revised form: 22

March 2021

Accepted: 25 March 2021

Available Online: 28 July

2021

\section{Keywords:}

Spirulina platensis,

Ocimum bacilicum,

Volatile compounds

DOI:

https://doi.org/10.26656/fr.2017.5(S3).010

\begin{abstract}
Microalgae Spirulina platensis contains high protein which can be used as functional food, but it has several undesirable volatile compounds. Ocimum basilicum contains various essential oils from the monoterpene class that can be used to reduce volatile compounds causing an off-odour in Spirulina platensis. This study was conducted to evaluate the intervention of $O$. basilicum on nature and microencapsulated $S$. platensis powder after $O$. basilicum treatment against the volatile compounds. The research consisted of two intervention models. S. platensis powder soaked with basil extract (1:4, $\mathrm{w} / \mathrm{v}$ ) and then dried by freeze-drying method without microencapsulation (DSB). The $S$. platensis powder was soaked in basil extract $(1: 4, \mathrm{w} / \mathrm{v})$ then dried by freeze-drying method and microencapsulated (MSB) after. Spirulina platensis powder was used as a control (SP). A solid-phase microextraction was used with the combination of GC-MS to identify volatile compounds. The results showed that the main volatile compounds in Spirulina are medium-chain alkanes. Other compounds that contributed to this off-odour are geosmin $(0.02 \%)$, 2-Methylisoborneol $(0.28 \%), \beta$-ionone (4.94\%). The intervention of $O$. basilicum in S. platensis resulted in a decrease in these volatile compounds. Geosmin was not detected by intervention with $O$. basilicum either by microencapsulation (MSB) or without microencapsulation (DSB). Therefore, the intervention of O. basilicum can reduce off-odour in $S$. platensis and can be applied as a functional food.
\end{abstract}

\section{Introduction}

Spirulina platensis is a biomass of cyanobacteria as a single cell protein producer which is rich in protein, essential vitamin and minerals, making it very appropriate to be used as a food source (Jung et al., 2019; Kameshwari et al., 2020). The amino acids composition Spirulina protein is among the best, exceeding the amino acids in soybeans, useful as a protein supplement in the treatment of malnutrition in children (Saranjaj and Sivasakthi, 2014). Spirulina platensis contains bioactive compounds such as phenols, phycocyanin and polysaccharide which have bioactive as antioxidants, anti-inflammation and immunostimulants. The use of Spirulina as a functional food provides various human health benefits (Finamor et al., 2017). However, Spirulina added to food can reduce sensory characteristics in the presence of an off-odour (Agustini et al., 2019).
The most common volatile compounds produced by cyanobacteria are geosmin and 2-methylisoborneol which causes a muddy-earthy-musty type flavour. Apart from these compounds, medium-chain alkane, $\beta$-ionone, $\beta$-cyclocitral are the main off-odour compounds in Spirulina (Suurnakki et al., 2015; Milovanović et al., 2015). Geosmin and 2-Methylisoborneol have very low human sensory limits, they are disliked by consumers even at low concentrations (Lindholm-Lehto et al., 2019).

Ocimum basilicum is an aromatic plant that produces essential oils with a distinctive mint aroma. Essential oil is used in providing flavour and aroma to food to increase consumer acceptance of a product (Shaaban et al., 2012; Trivedi et al., 2014). Aromatic plants contain essential oils that play a specific role in aromas, such as chavicol, linalool and eugenol. The compounds are used in the food industry to reduce off-odours and act as an antioxidant (Kiferle et al., 2011; Barros et al., 2013; 
Koroch et al., 2017). The instability of essential oil in $O$. basilicum characterised by its susceptibility to oxygen, temperature and light whereby it requires microencapsulation to maintain its aroma and bioactivity (Majeed et al., 2015).

Microencapsulation can be used to protect active compounds during the processing and storage stages. This technique has been widely used to mask taste and aroma to enhance the organoleptic properties of a product. Microencapsulation is also used in a significant reduction in aromatic odours considering it as a more user-friendly product when dealing with an unpleasant odour (Gondal et al., 2017). Limited information on the intervention of a substance against volatile compounds to increase Spirulina consumption is available. Several studies on Spirulina to date were used as nutraceuticals and pharmaceuticals (Sowjanya and Manjula, 2016). However, the aroma and taste of $S$. platensis have not been studied further. The objective of this study was to evaluate the intervention of $O$. basilicum extract on Spirulina powder and microencapsulation treatment against volatile compounds.

\section{Materials and methods}

\subsection{Materials}

Spirulina powder was obtained from Brackishwater Aquaculture Fisheries (BBPBAP) Jepara (Central Java, Indonesia) in 2019. O. basilicum was purchased from a traditional market in Semarang, Central Java. This study covers treatments of Spirulina platensis powder that was not soaked in $O$. basilicum as a control sample (SP), S.platensis powder soaked with basil extract $(1: 4, \mathrm{w} / \mathrm{v})$ then dried by freeze-drying method without microencapsulation (DSB) and $S$. platensis powder soaked with basil extract $(1: 4, w / v)$ then dried by freezedrying method and then microencapsulated (MSB). Spirulina powder was soaked with $O$. basilicum leaf extract $(1: 4, w / v)$ and microencapsulation was conducted using maltodextrin (CV. Multi Kimia Raya, Semarang, Indonesia) combined with gelatin (Xian, Biof BioTechnology, Cina) with the concentration of 9:1 (w/w). The drying process used was the freeze-drying method (Heto Powerdry LL 1500, Germany) with a temperature of $-100^{\circ} \mathrm{C}$ for 48 hours. Sample preparation for the intervention of $O$. basilicum in Spirulina was conducted as previously described by Handiani et al. (2019).

\subsection{Solid-phase micro extraction analysis}

Solid-phase micro extraction (SPME) analysis was carried out with 30 mins exposure to a $2 \mathrm{~cm} \mathrm{DVB/CAR/}$ PDMS fibre followed by analyte desorption at $220^{\circ} \mathrm{C}$ for 3 mins. Briefly, $3.5 \mathrm{~g}$ of $S$. platensis powder in $22 \mathrm{~mL}$ SPME bottles are heated to $80^{\circ} \mathrm{C} .10 \mathrm{ppm}$ of methanol
(Sigma-Aldrich, Saint Louis, MO, USA) was added as an internal standard. Sample preparation stages such as extraction, purification, and concentration are combined into one step and one device that was directly connected to the Gas Chromatography Mass Spectrophotometer (Hulburt et al., 2009).

\subsection{GC-MS analysis}

The samples were run on a GC Agilent 7890A and MS 5975C with a Triple Axis detector. A $30 \mathrm{~m}$ x $250 \mu \mathrm{m}$ i.d. capillary column HP-5MS (J and W Scientific, folsom, USA) with $0.25 \mu \mathrm{m}$ stationary phase was used. Helium was used as a carrier gas at a flow rate of 1.8 $\mathrm{mL} / \mathrm{min}$. The oven was initially held for $1 \mathrm{~min}$ at $50^{\circ} \mathrm{C}$, then gradually increased by $3^{\circ} \mathrm{C} / \mathrm{min}$ to $120^{\circ} \mathrm{C}$ for $1 \mathrm{~min}$. Then, at a temperature of $5^{\circ} \mathrm{C} / \mathrm{min}$ to $220^{\circ} \mathrm{C}$ which was retained for $0 \mathrm{~min}$. The ions of volatile compounds in $S$. platensis were observed over a period of $100 \mu \mathrm{s}$. The quantity of each volatile compound from Spirulina and intervention $O$. basilicum in powder and Spirulina microencapsulation were evaluated.

\subsection{Identification and quantification of volatile compounds}

Identification of all volatile compounds obtained SPME analysis on the comparison of experimentally obtained compounds mass spectra with mass spectra available in NIST14 database. The quantification analysis was performed using Advanced Chemistry Development through the integration of the peak area of the chromatograms.

\section{Results and discussion}

The chromatographic profile was investigated to identify peaks of major and minor volatile compounds in each sample as shown in Figures 1 - 3. The result obtained from the determination of volatile compounds from the intervention of $O$. basilicum in Spirulina powder and microencapsulation was shown as \% chromatographic peaks of the total ion chromatogram (Table 1). The result showed that medium-chain alkanes were the main component of the volatile compounds in Spirulina. It has been proven that cyanobacteria have the capacity to produce natural hydrocarbon from fatty acids (Coates et al., 2014). The enzyme responsible for alkane production in cyanobacteria are acyl-acyl carrier protein (Acyl-ACP) reductase (AAR) and aldehydedeformulating oxygenase (ADO). These two enzymes work in series and in a complex manner which efficiently converts long-chain fatty acyl ACP or fatty acyl CoA into hydrocarbons (Gao et al., 2020). Pentadecane, hexadecane and heptadecane are the main hydrocarbon compounds in cyanobacteria (Milovanović 


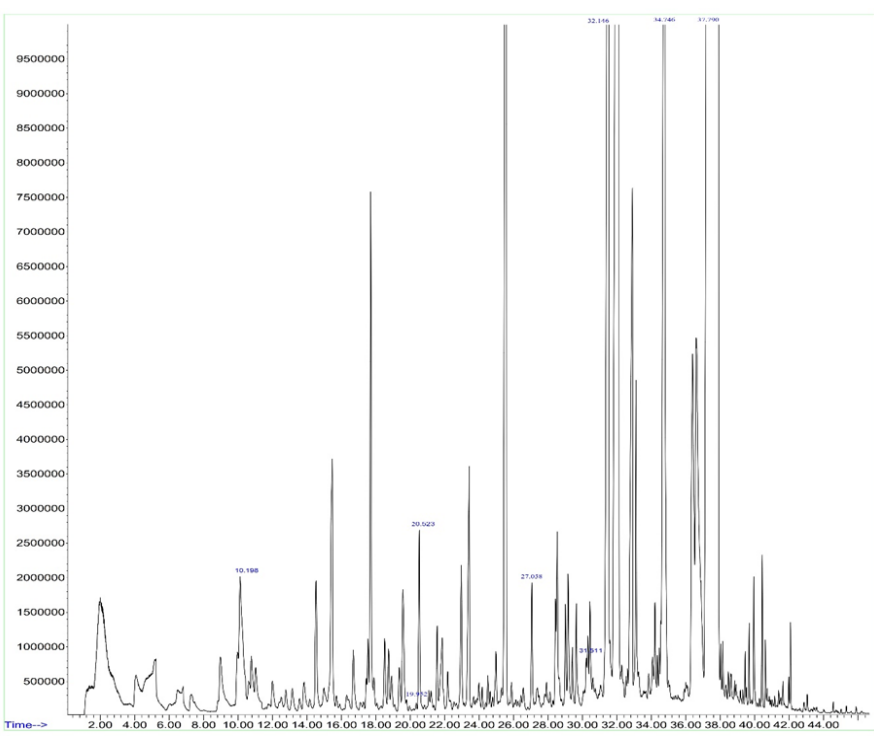

Figure 1. Chromatogram of the volatile compounds of Spirulina platensis (SP)

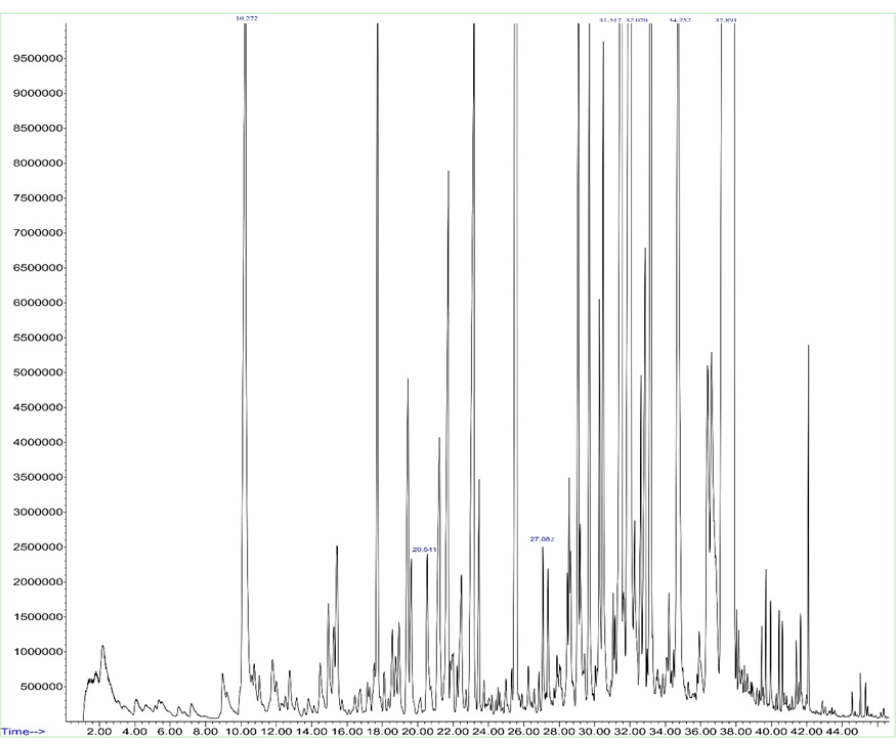

Figure 2. Chromatogram of the volatile compounds of DSB sample

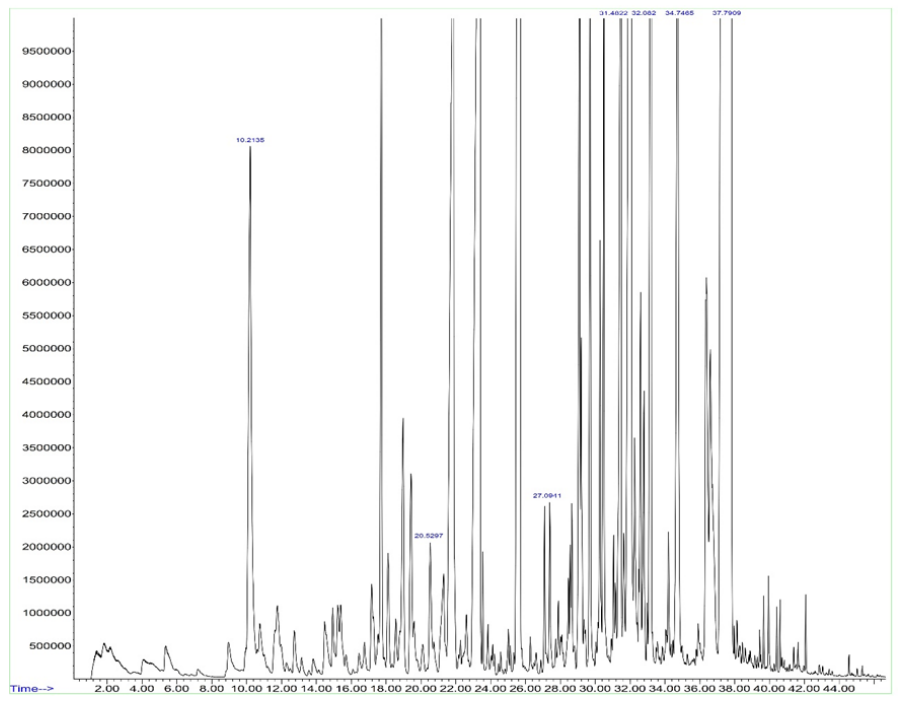

Figure 3. Chromatogram of the volatile compounds of MSB sample

Table 1. Volatile compounds detected in the samples (SP, DSB and MSB)

\begin{tabular}{lcccccc}
\hline \multirow{2}{*}{ Volatile compounds } & \multicolumn{3}{c}{ SP } & \multicolumn{2}{c}{ DSB } & \multicolumn{2}{c}{ MSB } \\
\cline { 2 - 7 } 2-Pentylfuran & RT & \% area & RT & \% area & RT & \% area \\
Geosmin & 10.198 & 0.31 & 10.2728 & 2.07 & 10.2135 & 1.54 \\
$\beta$-cyclocitral & 19.9529 & 0.02 & & - & & - \\
2-Methylisoborneol & 20.5237 & 0.41 & 20.5415 & 0.43 & 20.5297 & 0.43 \\
$\beta$-ionone & 27.0583 & 0.28 & 27.0821 & 0.29 & 27.0941 & 0.28 \\
Pentadecane & 31.5119 & 4.94 & 31.5177 & 4.27 & 31.4822 & 3.01 \\
Hexadecane & 32.1065 & 5.92 & 32.0707 & 4.3 & 32.0827 & 4.45 \\
Heptadecane & 34.7465 & 4.57 & 34.7523 & 3.64 & 34.7465 & 3.41 \\
\hline
\end{tabular}

et al., 2015).

The observation of SPME in the extraction of volatile compounds plays an important role in the formation of the distinctive aroma of Spirulina intervention of $O$. bacilicum, it can further be used for flavour analysis. The most important cause of the unpleasant taste and odour in Spirulina are geosmin and 2-methylisoborneol which are detected by humans in small concentration levels. The odour threshold for geosmin is $15 \mathrm{ng} / \mathrm{L}$ and 2-methylisoborneol is $35 \mathrm{ng} / \mathrm{L}$ (Juttner and Wasten, 2007). However, many people detect geosmin and 2-methylisoborneol at lower concentration levels. Spirulina in this study naturally produces low concentration of geosmin, 2methylisoborneol, 2-pentylfuran, $\beta$-cyclocitral and $\beta$ ionone (Table 1). 2-pentylfuran is a volatile compound found in cyanobacteria (Milovanović et al., 2015). This compound is formed through the auto-oxidation of linoleic acid, the high amount of 2-Pentylfuran is in line 
with the high content of linoleic acid (Krishnamurthy et al., 1967; Xu et al., 2017). The conjugated diene radicals produced from the radical cleavage of 9-hydroxy linoleate can react with oxygen to produce vinyl hydroperoxide, which will then undergo cyclization by alkoxy radicals form 2-pentylfuran (Frankel, 1983).

Ocimum basilicum intervention increased $\beta$ cyclocitral content in Spirulina, because $O$. basilicum contains citral compounds (da Costa et al., 2014). $\beta$ cyclocitral is a volatile compound that displays lytic activity on cyanobacteria. In particular, $\beta$-cyclocitral causes an attractive colour change from green to blue during the lysis process. $\beta$-cyclocitral provides distinctive properties with maximum absorption, thereby rapidly breaking down chlorophyll a and $\beta$-carotene (Harada et al., 2009). The threshold for $\beta$-cyclocitral volatile compounds is $750 \mathrm{nM}$. $\beta$-cyclocitral was not detected in live Mycrocystic cells, it was present only at very low concentration of $2.6 \mathrm{amol} / \mathrm{cell}$. Conversely, the rapid cell rupture activates the carotene oxygenase reaction, resulting in a high $\beta$-cyclocitral number, around $77 \pm 5.5 \mathrm{amol} / \mathrm{cell}$ calculated according to the maximum intracellular concentration of $2.2 \mathrm{mM}$ (Juttner et al., $2010)$. Similar to $\beta$-cyclocitral, $\beta$-ionone is one of the volatile compounds produced through the degradation of $\beta$-caroten cyanobacteria (Garcia-Plazaola et al., 2017).

Ocimum basilicum leaf extract can reduce geosmin compounds in powder and microencapsulation of Spirulina. This is because the essential oil content in $O$. basilicum can dissolve geosmin compounds. Essential oil from grape seeds efficiently decreases the concentration of geosmin (Lisanti et al., 2014). Whereas, 2Methylisoborneol cannot be reduced by the essential oil in $O$. bacilicum. This is due to the isoborneol content found in its essential oils (Joshi, 2013), therefore the 2methylisoborneol content increases in S. platensis with $O$. basilicum intervention. Microencapsulation is carried out to maintain the pleasant aroma created by the intervention of $O$. basilicum in $S$. platensis, therefore increasing its consumption and application in functional food as well as for nutraceutical and pharmaceutical products. da Silva et al. (2014) explained that microencapsulation is a technology used in the food industry, one of which is to maintain the aroma of the product. Microencapsulation maintains the stability of aroma or taste during the processing and storage stage to minimize degradation or loss of aroma. In addition, it can improve the quality of the finished product and increase customer satisfaction (Gupta et al., 2016). The aroma encapsulation of essential oils also allows for controlled release (Maes et al., 2019).

The intervention of $O$. basilicum in Spirulina powder without microencapsulation

(DSB)

or microencapsulation (MSB) produced a new volatile compound which results in a new aroma. Vittal et al. (2019) describe the extraction of petrichor and essential oils for the production of new fragrance because they produce a pleasant odour from the linalool compound (Elsharif et al., 2015). Stanojevic et al. (2018), explained that $O$. basilicum contains 65 active compounds and the highest content are $31.6 \%$ linalool and $23.8 \%$ methyl chavicol. Toncer et al. (2017) explained further that when plants experience flower growth the content of monoterpenes such as linalool increases and decreases along with the completion of the flowering period. The volatile compounds have their respective aroma descriptions. The combination of volatile compounds will cause a distinctive flavour. Essential oils are volatile liquid aroma components that are usually obtained from plants (Hamid et al., 2011).

\section{Conclusion}

To conclude, the essential oil in $O$. basilicum reduces volatile compounds such as geosmin, $\beta$ cyclocitral, $\beta$-ionone which causes an off-odour in the powder and Spirulina microcapsule. Linalool is a monoterpene compound useful for its purpose in flavour. Therefore, the intervention of $O$. basilicum in $S$. platensis can be applied as a functional food as well as a nutraceutical and pharmaceutical product.

\section{Conflict of interest}

The authors declare no conflict of interest.

\section{Acknowledgments}

The research funded by the PMDSU (Program of Master Degree Leading to Doctoral Degree for Excellent Graduates) from Ministry of Research and Technology, Indonesian Republic in the fiscal year of 2019-2021.

\section{References}

Agustini, T.W., Dewi, E.N., Amalia, U. and Kurniasih, R.A. (2019). Application of basil leaf extracts to decrease Spirulina platensis off-odour in increasing food consumption. International Food Research Journal, 26(6), 1789-1794.

Barros, N.A., Rocha, R., de Asis, A.R. and Medes, M.F. (2013). Extraction of basil oil (Ocimum basilicum L.) using supercritical fluid. III Iberoamerica Conference on Supracriticals Fluids Cartagene de Indias. Colombia.

Coates, R.C., Podell, S., Korobeynikov, A., Lapidus, A., Pevzner, P., Sherman, D.H., Allen, E.E., Gerwick, L. and Gerwick, W.H. (2014). Characterization of cyanobacterial hydrocarbon composition and 
distribution of biosynthetic pathway. PLoS ONE, 9 (1), e0085140. https://doi.org/10.1371/ journal.pone. 0085140

da Costa, A.S., Arrigoni-Blank, M.F., Filho, J.L.S.C., Santana, A.D.D., Santos, D.A., Alves, P.B. and Blank, A.F. (2015). Chemical diversity in basil (Ocimum sp.) Germplasm. The Scientific World Journal, 2015, $352638 . \quad$ https:// doi.org/10.1155/2015/352638

da Silva, J.K., Batista, A.G., Cazarin, C.B.B., Dionisio, A.P., de Brito, E.S., Marques, A.T.B. and Junior, M.R.M. (2017). Functional tea from a Brazilian berry: overview of the bioactive compounds. Food Science and Technology, 75(Part B), 292-298. https://doi.org/10.1016/j.lwt.2016.06.016

Elsharif, S., Buettner, A. and Banerjee, A. (2015). Structure-odour relationship of linalool, linalyl acetate and their corresponding oxygenated derivates. Frontiers in Chemistry, 3(57), 1-10. https://doi.org/10.3389/fchem.2015.00057

Finamor, A., Palmery, M., Bensehaila, S. and Peluso, I. (2017). Antioxidant, immunomodulating, and microbial-modulating activities of the sustainable and ecofriendly Spirulina. Oxidative Medicine and Cellular Longevity, 2017, 3247528. https:// doi.org/10.1155/2017/3247528

Frankel, E.N. (1983). Volatile lipid oxidation products. Progress in Lipid Research, 22(1), 1-33. https:// doi.org/10.1016/0163-7827(83)90002-4

Gao, Y., Zhang, H., Fan, M., Jia, C., Shi, L., Pan, X., Cao, P., Zhao, X., Chang, W. and Li, M. (2020). Structural insights into catalytic mechanism and product delivery of cyanobacterial acyl-acyl carrier protein reductase. Nature Communications, 11(1), 111. https://doi.org/10.1038/s41467-020-15268-y

Garcia-Plazaola, J.I., Portillo-Estrada, M., FernandezMarin, B., Kannaste, A. and Niinemets, U. (2017). Emissions of carotenoid cleavage product upon heat shock and mechanical wounding from a foliose lichen. Environmental and Experimental Botany, 133, 1-33. https://doi.org/10.1016/ j.envexpbot.2016.10.004

Gondal, S.A., Abbas, N. and Hussain, A. (2017). Microencapsulation: a taste and odour masking approachfor garlic (Allilum sativum) powder. British Journal of Pharmacy, 2(2), 19-20. https:// doi.org/10.5920/bjpharm.2017.19

Gupta, S., Khan, S., Muzafar, M. and Kushwaha, M. (2016). Encapsulation: entrapping essential oil/ flavours/aromas in food. In Encapsulations, p. 229268. Academic Press. https://doi.org/10.1016/B978-0 $-12-804307-3.00006-5$
Hamid, A.A., Aiyelagbe, O.O. and Usman, L.A. (2011). Essential oils: its medicinal and pharmacological uses. International Journal Current Research, 3(2), 86-98.

Handiani, E.T., Amalia, U., and Agustini, T.W. (2019). The effect of basil (Ocimum basilicum i.)leaf extract in immersion stage againts Profile of volatile compound on Spirulina platensis Powder. IOP Conference Series: Earth and Environmental Science, 246, 012057. http://doi.org/10.1088/175551315/246/1/012057

Harada, K.I., Ozaki, K., Tsuzuki, S., Kato, H., Hasegawa, M., Kuroda, E.E., Arii, S. and Tsuji, K. (2009). Blue color formation of cyanobacteria with $\beta$ -cyclocitral. Journal Chemical Ecology, 35(11), 1295-1301. http://doi.org/10.1007/s10886-009-97065

Hurlburt, B., Lyoid, S.W. and Grimm, C.C. (2009). Comparison of Analytical techniques for detection of geosmin and 2-methylisoborneol in aqueous sample. Journal of Chromatograpic Science, 47(8), 670-673. http://doi.org/10.1093/chromsci/47.8.670

Joshi, R.K. (2013). Chemical composition of the essential oil of camphor basil (Ocimum kilimandscharicum Guerke). Global Journal of Medicinal Plant Research, 1(2), 207-209.

Jung, F., Kruger-Genge, A., Weldeck, P. and Kupper, J.H. (2019). Spirulina platensis, a super food. Journal of Cellular Biotechnology, 5(1), 43-54. http://doi/org/10.3233/JCB-189012

Juttner, F. and Watson, S.B. (2007). Biochemical and ecological control of geosmin and 2methylisoborneol in source waters. Applied and Environmental Microbiology, 73(14), 4395-4406. http://doi.org/10.1128/AEM.02250-06

Juttner, F., Waston, S.B., Elert, E.V. and Koster, O. (2010). $\beta$-Cyclocitral, a grazer defence signal unique to the cyanobacterium Microcystis. Journal Chemical Ecology, 36(12), 1387-1397. http:// doi.org/ 10.1007/s10886-010-9877-0

Kameshwari, V., Selvakumar, S. and Sangeeta, S. (2020). Single cell protein spirulina - a nutrient treasure. Research Journal of Pharmacology and Pharmacodinamics, 12(2), 49-54. https:// doi.org/10.5958/2321-5836.2020.00010.5

Kiferle, C., Lucchesini, G.M., Mensuali-Sodi, A., Manggaini, R., Riffaelli, A. and Pardossi, A. (2011). Rosmarinic acid content in basil plantt grown in vitro and hydroponics. Central European Journal of Biology, 6(6), 946-957. http://doi.org/10.2478/ s11535-011-0057-1

Koroch, A.R., Simon, J.E. and Juliani, H.R. (2017). 
Essential oil composition and purple basil their reverted green varieties (Ocimum basilicum L.) and their associated biological activity. Industrial Crops and Product, 3(1), 62-79. https://doi.org/10.1016/ j.indcrop.2017.04.066

Krishnamurthy, R.G., Smouse, T.H., Mookherjee, B.D. and Reddy, B.R. (1967). Identification of 2pentylfuran in fat and oils and its relationship to the reversion flavor soybean oil. Journal of Food Science, 32(4), 372-374. https://doi.org/10.1111/ j.1365-2621.1967.tb09687.x

Lindholm-Lehto, P.C., Velma, J., Pakanen, H. and Alen, R. (2019). Depuration of geosmin and 2methylisoborneol induced off-flavors in recirculating aquaculture system (ras) farmed European whitefish Coregonus lavaretus. Journal Food Science Technology, 56(10), 4585-4594. https:// doi.org/10.1007/s13197-019-03910-7

Lisanti, M.T., Gambuti, A., Genovesa, A. and Piombino, P. (2014). Earthy off-flavour in wine: evaluation of remedial treatments for geosmin contamination. Food Chemistry, 154, 171-178. https:// doi.org/10.1016/j.foodchem.2013.12.100

Maes, C., Bouquillon, S. and Fauconnier, M.L. (2019). Encapsulation of essential oils for the development of biosourced pesticides with controller release: a review. Molecules, 24(14), 1-17. https:// doi.org/10.3390/molecules24142539

Majeed, H., Bian, Y.Y., Ali, B., Jamil, A., Majeed, U., Khan, Q.F., Iqbal, K.J., Shoemaker, C.F. and Fang, Z. (2015). Essential oil encapsulation: uses, procedures, and trends. Royal Society and Chemistry, 5(72), 55449-55463. https://doi.org/10.1039/ C5RA06556A

Milovanović, I., Mišan, A., Simeunović, J., Kovač, D., Jambree, D. and Mandić, A. (2015). Determination of volatile organic compounds in selected strains of cyanobacteria. Journal of Chemistry, 2015, 969542. https://doi.org/10.1155/2015/969542

Saranjaj, P. and Sivasakthi, S. (2014). Spirulina platensis - food for future: a review. Asian Journal of Pharmaceutical Science and Technology, 4(1), 2633.

Shaaban, H.A.E., El-Ghorab, A.H. and Shibamoto, T. (2012). Bioactivity of essential oil and their volatile aroma components: review. Journal of Essential Oil Research, 24(2), 203-212. https:// doi.org/10.1080/10412905.2012.659528

Sowjanya, M. and Manjula, K. (2016). Dietary Spirulina in pharmaceutical and nutraceutical applications. International Journal of Science and Research, 5(7), 225-227.
Stanojevic, L.P., Marjanovic-Balaban, Z.R., Kalaba, V.D., Stanojevic, J.S., Cvetkovic D.J. and Cakic, M.D. (2018). Chemical composition, antioxidant and antimicrobial activity of basil (Ocimum basilicum L.) essential oil. Journal of Essential Oil Bearing Plants, 20(6), 1557-1569. https:// doi.org/10.1080/0972060X.2017.1401963

Suurnakki, S., Gomes-Saez, G.V., Ylinen, A. and Jokela, J. (2015). Identification of geosmin and 2methylisoborneol in cyanobacteria and molecular detection methods for the producers of these compounds. Water Research, 68, 56-66. https:// doi.org/10.1016/j.watres.2014.09.037

Toncer, O., Karaman, S., Diras, E. and Tansi, S. (2017). Essential oil composition of Ocimum basilicum 1. at different phenologicals stage in semi-arid and environmental condition. Fresenius Environmental Bulletin, 26(8), 5441-5446.

Trivedi, V.B., Prajapati, J.P., Pinto, S.V. and Darji, V.B. (2014). Use of basil (Tulsi) As flavouring ingredient in the manufacture of ice cream. American International Journal of Contemporary Scientific Research, 1(3), 28-43.

Vittal, A., Srikanth, B.S., Manokaran, S. and Reddy, A.H.M. (2019). Extraction of petrichor and essential oils for the production of novelty fragrance product. Journal Pharmaceuticals Sciences and Research, 11 (6), 2168-2173.

Xu, L., Yu, X., Li, M., Chen, J. and Wang, X. (2017). Monitoring oxidative stability and changes in key volatile compounds in edible oils during ambient storage through HS-SPME/ GC-MS. International Journal of Food Properties, 20(S3), 2926-2938. https://doi.org/10.1080/10942912.2017.1382510 